\title{
INTERNAL FIXATION OF VOLAR-DISPLACED DISTAL RADIAL FRACTURES
}

\author{
J. F. KEATING, C. M. COURT-BROWN, M. M. MCQUEEN
}

From the Royal Infirmary of Edinburgh, Scotland

We reviewed a series of $\mathbf{7 9}$ distal radial fractures with volar displacement which had been fixed internally using a buttress plate. The fractures were classified using the Frykman and AO systems; $59 \%$ were intraarticular.

Complications occurred in $\mathbf{4 0 . 5 \%}$ of cases; malunion was most frequent $(\mathbf{2 8 \%})$. Functional recovery in patients with malunion was significantly worse than in those with good anatomical restoration $(p<0.001)$. The AO and Frykman classifications and the degree of restoration of volar tilt were predictive of outcome.

J Bone Joint Surg [Br] 1994; 76-B:401-5.

Received 20 May 1993; Accepted after revision 19 October 1993

Credit for describing the volar-displaced fracture of the distal radius is usually given to Smith who published his account in 1847 , although marginal distal radial fractures with dorsal or volar displacement had been described some years earlier by Barton (Peltier 1984). Both names are now used eponymously for distal radial fractures with volar displacement. There have been few reports on the treatment and outcome of these injuries and the early papers are lacking in detail (Thomas 1957; Ellis 1965). Immobilisation in a plaster cast was the most common method of treatment (Mills 1957; Flandreau, Sweeney and O'Sullivan 1962; Paterson 1966; Woodyard 1969) but maintaining reduction in a cast can be difficult with unstable fractures (Fuller 1973) and particularly with the displaced volar marginal fracture (De Oliveira 1973; Thompson and Grant 1977; Pattee and Thompson 1988; Mehara et al 1993).

Recent reports have focused on operative management (Smith et al 1988; van Leeuwen et al 1990; van Raay and van der Werken 1991; Mehara et al 1993) and

J. F. Keating, FRCS, Senior Orthopaedic Registrar

C. M. Court-Brown, MD, FRCS Ed(Orth), Consultant Orthopaedic Surgeon M. M. McQueen, FRCS Ed(Orth), Senior Lecturer and Consultant Orthopacdic Surgeon

Department of Orthopaedics, Royal Infirmary of Edinburgh, 1 Lauriston Place, Edinburgh EH3 9YW, UK.

Correspondence should be sent to Miss M. M. McQueen.

(C)1994 British Editorial Society of Bone and Joint Surgery $0301-620 X / 94 / 3707 \$ 2.00$ we have analysed our experience of patients treated by immediate internal fixation with a buttress plate. We present the early surgical results and the long-term outcome of hand and wrist function.

\section{PATIENTS AND METHODS}

Between April 1988 and June 1990, we treated a total of 1609 distal radial fractures at the Royal Infirmary, Edinburgh. Seventy-nine (4.9\%) of these had volar displacement; 23 were in men and 56 in women. The mean age of the patients was 55 years, but their age distribution was bimodal with a group of young adult men and a group of middle-aged or elderly women. The injury was due to a fall in 66 patients $(84 \%)$ and to highenergy trauma, usually a road-traffic accident, in the rest. Two fractures were open, with Gustilo grade-I and II wounds respectively.

The fractures were classified in accordance with the Frykman (1967) and the AO systems (Müller et al 1990). Surgery was performed at a mean of three days after injury (1 to 14). The standard volar approach to the distal radius was used to expose the fracture, which was reduced and fixed with a small-fragment AO T-plate. Screws were inserted into the distal fragment if the bone quality allowed. No bone grafts were used. A light synthetic below-elbow cast was worn for a period of 4 to 5 weeks and physiotherapy was given to mobilise the hand and wrist thereafter.

All the patients were personally followed up by the authors. Radiological examination was carried out postoperatively, at one and six weeks, and at final follow-up. In addition to the $A O$ and Frykman classification of the initial radiograph, three other measurements were made: radial shortening (Melone 1984), radial shift, and dorsal angulation (Van der Linden and Ericson 1981). Radiographs of the normal wrist were used for comparison and radial shift and shortening were expressed as the difference from the normal side. From comparison with the normal wrist, we defined malunion as $>2 \mathrm{~mm}$ of radial shortening, $>4 \mathrm{~mm}$ of radial shift, $>15^{\circ}$ of volar tilt or $>10^{\circ}$ of dorsal tilt.

In 52 patients at a mean follow-up of 24 months (12 to 49) the function of both hands and wrists was tested by an occupational therapist with no knowledge of the radiological measurements. The tests have been pre- 
viously reported (McQueen and Caspers 1988). Grip strength was assessed using the Jamar dynamometer (Bechtol 1954) and Musur-Grieve spring balance (MusurGrieve 1984) with interchangeable handles to allow measurement of hook, cylinder, key, chuck and pinch grips. Grip endurance was tested on the latter apparatus using the hook grip. Manual dexterity was assessed using the Jebsen test (Jebsen et al 1969) supplemented by the Moberg test performed with the eyes open (Moberg 1958). The ranges of movement (flexion/extension, pronation/supination, radial/ulnar deviation) were measured by a goniometer. The unaffected side was used as a control in each case. The ability to perform unilateral and bilateral activities of daily living such as lifting weights, turning keys, using scissors etc, was assessed and scored (Sheehan, Sheldon and Marks 1983).

Statistical analysis of the results was carried out using the chi-squared test, one-way analysis of variance and multiple regression.

\section{RESULTS}

The Frykman classification showed an even distribution of types I to VI $(7,2,6,4,5$ and 4$)$ but the more severe patterns, types VII to VIII, predominated (17 and 30). The AO classification is more detailed and has 27 different subtypes. The A subtype, extra-articular fractures, was seen in 21 patients $\left(A_{2}=13 ; A_{3}=8\right)$ and the $B$ subtypes, volar intra-articular marginal fractures, in $29\left(B_{2}=2\right.$; $\left.B_{3}=27\right)$. The remaining 29 patients were of the $C$ subtype, complex intra-articular fractures $\left(C_{1}=11 ; C_{2}=9 ; C_{3}=9\right)$.

Complications occurred in 32 patients $(40.5 \%)$. Two forearm compartment syndromes developed within 24 hours of surgery, were treated by immediate fasciotomy, and had no sequelae at final review. One patient who was on Warfarin for medical reasons developed a haematoma in the wound that required evacuation six days post- operatively. Four patients had symptoms of median nerve compression before surgery and had carpal tunnel decompression performed at the time of the operation. A further three patients developed symptoms and signs of median nerve dysfunction within one month of surgery; all resolved spontaneously. Reflex sympathetic dystrophy occurred in two patients and only improved after prolonged periods of physiotherapy. Rupture of the extensor pollicis longus occurred in two patients at eight and ten weeks postoperatively; since functional impairment was slight they were not repaired. In one case there was failure of fixation of the implant.

Applying the radiological criteria outlined above, 22 (27.8\%) patients had malunion. The mean volar tilt of the uninjured wrists was $9.1^{\circ}$. Preoperatively, the mean value of the injured wrists was $14.4^{\circ}$, which was overcorrected to a mean of $5.7^{\circ}$ postoperatively. This was maintained to six weeks, but at final follow-up the overcorrection had increased to a mean value of $2.2^{\circ}$. Radial shift was a mean of $3.5 \mathrm{~mm}$ before surgery and improved to $0.5 \mathrm{~mm}$. A week later the mean shift was $2.2 \mathrm{~mm}$ and this was the same at final follow-up. Preoperatively, the mean radial shortening was $3.9 \mathrm{~mm}$. It was reduced postoperatively to $1.1 \mathrm{~mm}$ and at final follow-up to $1.4 \mathrm{~mm}$.

Five fractures were overcorrected into dorsal angulation, one was originally reduced and then drifted into dorsal angulation, and three healed with residual volar angulation. Fourteen patients had residual radial shortening at final review, one of whom also had dorsal angulation.

\section{Functional outcome}

Tests of grip strength. Of the functional tests performed, mass grip strength showed the most variable recovery. Only 18 patients (34.6\%) recovered grip strength to within $80 \%$ of the normal side, and $12(23 \%)$ recovered less than $50 \%$. Tests of grip endurance showed that 37 patients (71\%) recovered to within $80 \%$ of normal (Fig. 1a). Only

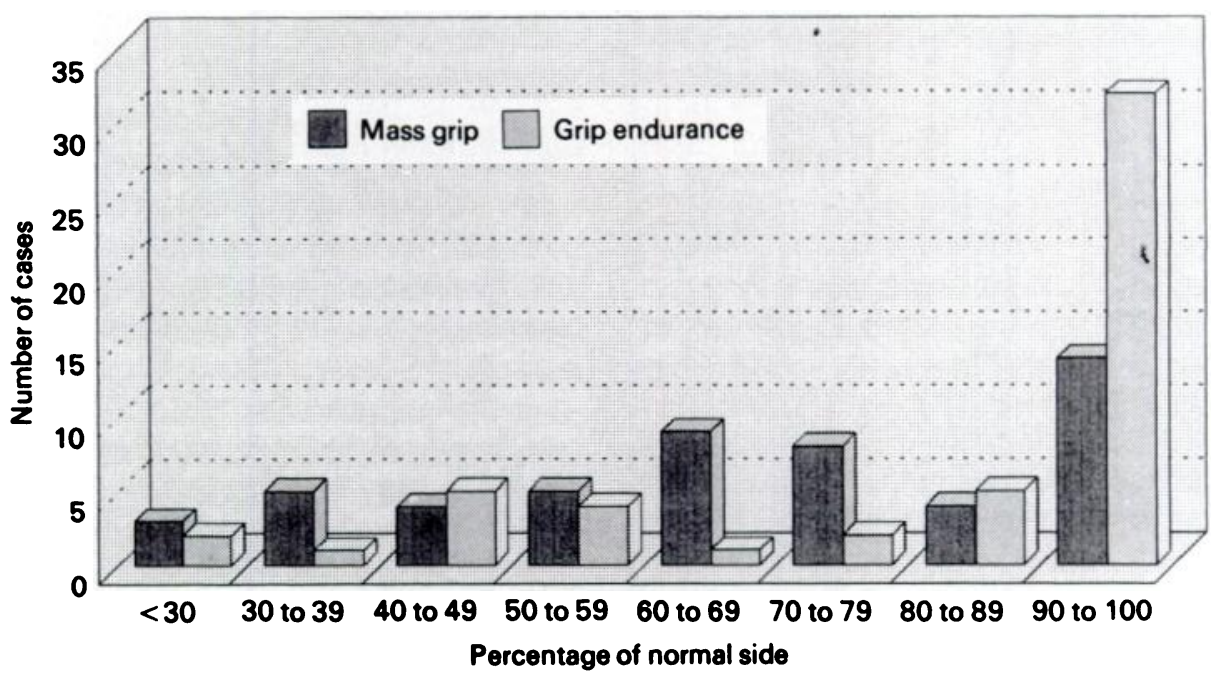

Fig. 1a

Mass grip strength and endurance measured by the Jamar dynamometer. 


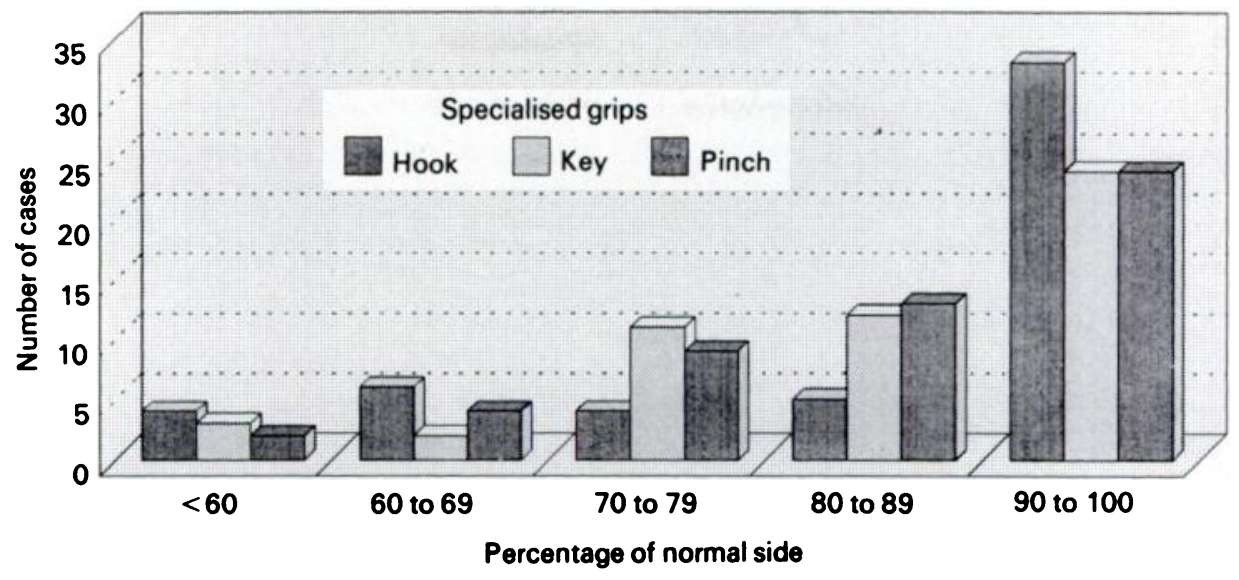

Fig. 1b

Specialised grip strengths measured by the Musur-Grieve spring balance. Values are expressed as percentages of the strength of the uninjured side.

eight patients (15.3\%) had a grip endurance less than $50 \%$ of normal. The specialised grip strengths, as tested by the Musur-Grieve spring balance, generally showed a more complete recovery. Assessment of key, hook and pinch grips showed that 35 of the 52 subjects tested $(67 \%)$ recovered to within $80 \%$ of the normal side for most assessments (Fig. 1b).

Wrist movement. Pronation and supination recovered best and were within $90 \%$ of the normal side in $24(46 \%)$ and $32(61 \%)$ patients respectively. Extension and radial deviation also showed good recovery with 35 patients (67\%) regaining movements to within $80 \%$ of the normal side. Flexion and ulnar deviation showed less recovery with only 17 patients $(32.7 \%)$ achieving $90 \%$ of the range of movement on the uninjured side.

Manual dexterity. The results of the Moberg and Jebsen dexterity tests were measured in seconds and were calculated as a percentage of the normal side. They showed an excellent recovery at follow-up; most patients could perform to within $90 \%$ of the normal side.

Since the most sensitive index of functional outcome was grip strength, multiple regression analysis was carried out to relate it to the radiological measurements and the classification of the fractures. The postoperative and subsequent measurements of volar tilt were significantly related to the functional outcome $(p<0.02)$. The degree of preoperative volar tilt was not related to the final functional performance nor was the magnitude of radial shift or radial shortening preoperatively $(p=0.4)$ or at follow-up $(\mathrm{p}=0.8)$.

The AO classification was significantly related to functional outcome. With the progression of fracture patterns from type $A$ to type $C$, there was a significant deterioration in grip strength and endurance $(p<0.05)$. This trend held true even for the subdivisions of each category and was not related to age; there was no significant difference in the mean ages of the patients in each subgroup (analysis of variance; $p=0.637$ ). The subdivision of fractures according to the Frykman classification also showed a statistically significant relationship between class and outcome of functional testing ( $p<0.04)$; it also had an even age distribution (analysis of variance; $p=0.9$ ).

Activities of daily living. Of the 52 patients who had functional assessment, 13 had malunion. Nine of these experienced difficulties with unilateral use of the injured wrist and six also had difficulty in performing bilateral hand and wrist functions. Of the 39 patients whose wrists were not deformed, seven had difficulty performing unilateral activities of daily living and five also encountered difficulty in bilateral activities. The differences in performance between those with and without malunion were significant for both unilateral and bilateral activities (chi-squared test with Yates correction; $p<0.001$ and $p=0.03$ respectively).

\section{DISCUSSION}

In recent years interest in the management of distal radial fractures has increased (Jupiter 1991) but most publications are about dorsally displaced fractures. Volar displaced fractures are relatively uncommon and after the first description by Smith (1847), no subsequent publication on the topic appeared until the report by Thomas in 1957. In most series, patient numbers have been small and detailed analysis of outcome lacking.

The classification of these fractures has been confused by their eponymous description as Barton's or Smith's fractures (Peltier 1984). The term Barton's fracture is particularly liable to cause confusion since it has been used to describe both volar displaced and dorsal marginal fractures (Thompson and Grant 1977). The classification proposed by Thomas (1957) has been the most widely used. He divided the injuries into three groups, with Barton's fracture called 'type-II Smith's fracture'. Other authors have considered Barton's mar- 
ginal fractures separately (De Oliveira 1973; Thompson and Grant 1977; Pattee and Thompson 1988).

Most papers in which Thomas' classification was used have given little indication of its relationship to the final outcome (Paterson 1966; Woodyard 1969; van Raay and van der Werken 1991). In one study of 49 patients treated operatively, Thomas' classification had no predictive value (van Leeuwen et al 1990). For accurate documentation, analysis and comparison of the results of treatment, we believe that a more relevant classification is therefore necessary.

The Frykman classification has been widely used but has the disadvantage that it gives no indication of the magnitude or direction of displacement. In the present series, however, it did have predictive value with regard to the functional outcome. The classification also has predictive value for the outcome of dorsally displaced distal radial fractures (Solgaard 1984). The value of this system is that it is easy to use in everyday practice.

The AO system is the most comprehensive classification so far devised for the description of distal radial fractures. Its main disadvantage is its complexity - it

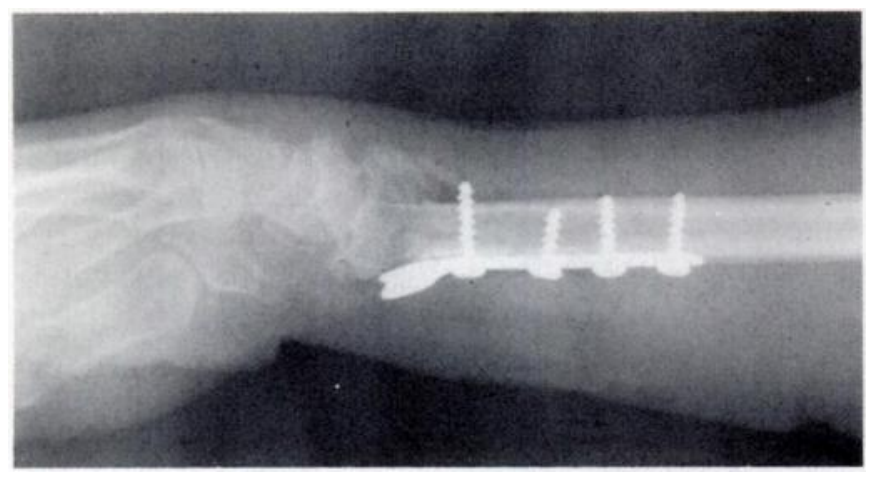

Fig. 2a
A fractures, we had $18(86 \%)$ good results. An advantage of surgical management is the avoidance of the need for an above-elbow cast which can sometimes result in lasting limitation of forearm rotation (Pool 1973). Internal fixation also surmounts the problem of maintaining reduction which is difficult in the case of volar marginal fractures (De Oliveira 1973; Thompson and Grant 1977; Pattee and Thompson 1988).

Our overall complication rate of $40.5 \%$ is high, but is similar to some other series (Cooney, Dobyns and Linscheid 1980; van Leeuwen et al 1990). A recent report of 16 of these fractures treated by external fixation revealed a high rate of reflex sympathetic dystrophy, but the series was too small to draw any firm conclusions about other complications (van Raay and van der Werken 1991).

The most common complication in our series was malunion, with dorsal tilt, but we applied stringent radiological criteria for its definition in contrast to other studies in which malunion has been poorly defined (Smith et al 1988; van Leeuwen et al 1990). Five of our failures arose because we did not adequately contour the plate,

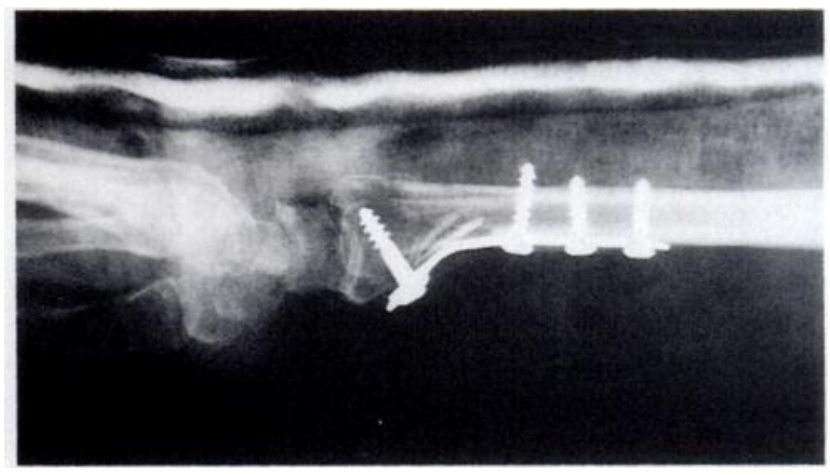

Fig. 2b

Figure $2 a$ - Radiograph showing overcorrection of the volar tilt into excessive dorsal angulation due to a poorly contoured plate. Figure $2 b$ - The position improved after the plate had been removed and recontoured.

includes 27 different subtypes - but it does have the advantage that every fracture pattern encountered can be precisely categorised. Our results suggest that the AO classification is also a useful prognostic guide to the final functional outcome. Larger numbers of distal radial fractures of all types need to be assessed to validate this conclusion.

Previous reports have recorded good results both from conservative and from operative treatment (Mills 1957; Ellis 1965; Bhattacharyya and Srivastava 1972; De Oliveira 1973; Fuller 1973; Smith et al 1988; van Leeuwen et al 1990; van Raay and van der Werken 1991) but no prospective randomised comparison of the two methods has been made. Conservative treatment has probably been used more commonly for the extra-articular fractures. Woodyard (1969) reported that 13 of 19 patients with extra-articular fractures had good results with this management. If his criteria are applied to our 21 AO type- resulting in excessive dorsal angulation of the distal fragment (Fig. 2). Many fractures, however, appeared adequately reduced in the postoperative radiographs, but underwent subsequent shortening. This tended to occur in fractures in which there was both dorsal and volar comminution.

Avoidance of malunion is important, since a poor anatomical result adversely affects recovery of function, as was reflected in the difficulties patients with malunion had with activities of daily living. This association has already been well documented for dorsally displaced wrist fractures (Porter and Stockley 1984; McQueen and Caspers 1988; Howard et al 1989). Our results suggest that restoration of the normal volar tilt is the single most important determinant of functional outcome. Neither radial shift nor, more surprisingly, radial length influenced the outcome to the same extent.

Despite the high rate of malunion, most of our 
patients achieved an acceptable level of function after rehabilitation and we believe that internal fixation with a buttress plate is a satisfactory method of treatment for these fractures. Proof that internal fixation is superior to cast treatment would require a prospective randomised trial. The analysis of radiological parameters in the present series indicated that in a proportion of these fractures there is loss of the initial reduction obtained at the time of surgery, mainly due to progressive radial shortening. It seems unlikely that treatment by cast or internal fixation alone can prevent this, since it is related to the degree of comminution of the fracture. It may be that adjunctive bone grafting would better maintain the length obtained by the operative reduction.

The authors would like to thank Mrs Carol Hajducka and Mrs Kath Anderson for their help with the radiographic and functional assessment.

Although none of the authors have received or will receive benefits for personal or professional use from a commercial party related directly or indirectly to the subject of this article, benefits have been or will be received but are directed solely to a research fund, foundation, educational institution, or other non-profit institution with which one or more of the authors is associated.

\section{REFERENCES}

Bechtol CO. Grip test: the use of a dynamometer with adjustable handle spacings. J Bone Joint Surg [Am] 1954; 36-A:820-4.

Bhattacharyya AN, Srivastava KK. Smith's fracture. Aust NZ J Surg $1972 ; 42: 141-4$.

Cooney WP III, Dobyns JH, Linscheid RL. Complications of Colles' fractures. J Bone Joint Surg [Am] 1980; 62-A:613-9.

De Oliveira JC. Barton's fractures. J Bone Joint Surg [Am] 1973; 55 A:586-94

Ellis J. Smith's and Barton's fractures: a method of treatment. J Bone Joint Surg [Br] 1965; 47-B:724-7.

Flandreau RH, Sweeney RM, O'Sullivan WD. Clinical experience with a series of Smith's fractures. Arch Surg 1962; 84:288-91.

Frykman G. Fracture of the distal radius including sequelae - shoulderhand-finger syndrome, disturbance in the distal radio-ulnar joint and impairment of nerve function: a clinical and experimental study. Acta Orthop Scand 1967; Suppl 108.

Fuller DJ. The Ellis plate operation for Smith's fracture. J Bone Joint Surg [Br] 1973; 55-B:173-8.

Howard PW, Stewart HD, Hind RE, Burke FD. External fixation or plaster for severely displaced comminuted Colles' fractures? J Bone Joint Surg [Br] 1989; 71-B:68-73.

Jebsen RH, Taylor N, Trieschmann RB, et al. An objective and standardized test of hand function. Arch Phys Med 1969; 50:311-9.
Jupiter JB. Current concepts review. Fractures of the distal end of the radius. J Bone Joint Surg [Am] 1991; 73-A:461-9.

van Leeuwen PA, Reynders PA, Rommens PM, Broos PL. Operative treatment of Smith-Goyrand fractures. Injury 1990; 21:358-60.

McQueen M, Caspers J. Colles' fracture: does the anatomical result affect the final function? J Bone Joint Surg /Br] 1988; 70-B:649-51.

Mehara AK, Rastogi S, Bhan S, Dave PK. Classification of volar Barton fractures. Injury 1993; 24:55-9.

Melone CP Jr. Articular fractures of the distal radius. Orthop Clin North Am 1984; 15(2):217-36.

Mills TJ. Smith's fracture and anterior marginal fracture of radius. $\mathrm{Br}$ Med $J$ 1957; 2:603-5.

Moberg E. Objective methods for determining the functional value of sensibility in the hand. J Bone Joint Surg /Br] 1958; 40-B:454-76.

Müller ME, Nazarian S, Koch P, Schatzker J. The comprehensive classification of fractures of long bones. Berlin, etc: Springer-Verlag, 1990.

Musur-Grieve M. Methods of assessment and management of the rheumatoid hand at the Institute of Rheumatology, Warsaw, Poland. In: Hunter JM, Schneider CH, Mackin EJ, Callahan AD, eds. Rehabilitation of the hand. 2nd ed. St Louis, etc: CV Mosby Co, 1984:651-62.

Paterson DC. Smith's fracture: a review. Aust NZ J Surg 1966; 36:145-52.

Pattee GA, Thompson GH. Anterior and posterior marginal fracturedislocations of the distal radius: an analysis of the results of treatment. Clin Orthop 1988; 231:183-95.

Peltier LF. Fractures of the distal end of the radius: an historical account. Clin Orthop 1984; 187:18-22.

Pool C. Colles' fracture: a prospective study of treatment. $J$ Bone Joint Surg [Br] 1973; 55-B:540-4.

Porter ML, Stockjey I. Functional index: a numerical expression of posttraumatic wrist function. Injury $1984 ; 16: 188-92$.

van Raay JJ, van der Werken C. External fixation of Smith's fracture. Acta Orthop Scand 1991; 62:284-7.

Sheehan NJ, Sheldon JF, Marks D. Grip strength and torquometry in the assessment of hand function in patients with rheumatoid arthritis. $\mathrm{Br} J$ Rheumatol 1983; 22:158-64.

Smith RS, Crick JC, Alonso J, Horowitz M. Open reduction and internal fixation of volar lip fractures of the distal radius. J Orthop Trauma $1988 ; 2: 181-7$.

Solgaard S. Classification of distal radius fractures. Acta Orthop Scand 1984; 56:249-52.

Thomas FB. Reduction of Smith's fracture. J Bone Joint Surg [Br] 1957; 39-B:463-70.

Thompson GH, Grant TT. Barton's fractures - reverse Barton's fractures: confusing eponyms. Clin Orthop 1977; 122:210-21.

Van der Linden W, Ericson R. Colles' fracture: how should its displacement be measured and how should it be immobilized? J Bone Joint Surg [Am] 1981; 63-A:1285-8.

Woodyard JE. A review of Smith's fractures. J Bone Joint Surg [Br] 1969; 51-B:324-9. 